\title{
Comparison of Alternaria spp. Collected in Italy from Apple with $A$. mali and Other AM-Toxin Producing Strains
}

\author{
F. Rotondo, M. Collina, A. Brunelli, and B. M. Pryor
}

First, second, and third authors: Alma Mater Studiorum University of Bologna, Department of Agri-food Protection and Improvement (Diproval), Viale Fanin, 46 Bologna, Italy; and first and fourth authors: University of Arizona, Department of Plant Sciences, P.O. Box 210036, Tucson.

Accepted for publication 20 August 2012.

\begin{abstract}
Rotondo, F., Collina, M., Brunelli, A., and Pryor, B. M. 2012. Comparison of Alternaria spp. collected in Italy from apple with A. mali and other AM-toxin producing strains. Phytopathology 102:1130-1142.

Since 1999, a disease of apple caused by an Alternaria sp. has been affecting orchards in northern Italy resulting in necrotic spots on leaves and on fruit. Forty-four single-spored isolates were obtained from diseased plant materials to investigate the diversity of this fungus in Italy and to compare these isolates to isolates of Alternaria associated with apple disease in previous studies, including A. mali, causal agent of apple blotch. All isolates, including the reference strains, were tested for pathogenicity utilizing in vitro bioassays on detached leaf or on fruit ('Golden Delicious'). In addition, morphological characterizations were conducted describing both the three-dimensional sporulation pattern and the colony morphology of each isolate. In order to assess the genetic diversity within

the Italian Alternaria population, sequence characterization of specific loci and anonymous regions (endoPG, OPA1-3, OPA2-1, and OPA10-2) and genetic fingerprinting based on amplified fragment length polymorphism and inter simple sequence repeat markers were performed. The single spore isolates exhibited differential pathogenicity, which did not correlate with the morphological groupings or to groupings defined by molecular approaches. Moreover, 10 pathogenic isolates out of the 44 single-spored tested were positive for the host-specific AM-toxin gene based upon polymerase chain reaction amplification using specific primers for the AM-toxin gene. This suggests that the production of the AM-toxin may be involved in pathogenesis by some of the Italian isolates of $A$. alternata from apple. However, this research also suggests that a number of different Alternaria genotypes and morphotypes may be responsible for the apple disease in Italy and that a single taxon cannot be defined as the sole causal agent.
\end{abstract}

The genus Alternaria encompasses approximately 250 species and can be found worldwide in nearly every ecosystem. The genus is represented by both saprobes and plant pathogens, although species representing the two different lifestyles are not easily distinguished due to the ability of individual taxa to shift from saprophytic to parasitic strategy when a weakened host is encountered (50). As plant pathogens, Alternaria spp. collectively infect a diversity of plants (cereals, vegetables, and fruits) causing severe damage and substantial crop loss. Moreover, a wide number of species are destructive postharvest pathogens and are known producers of toxic secondary metabolites (60).

Characterization of species within Alternaria has historically been based on morphological features of the conidia and the sporulation apparatus, and these characters have been used to create morphologically defined species-groups typified by representative Alternaria species $(5,46,55)$. Prominent among these groups are the large-spored porri species-group and the smallspored alternata species-group. Subsequent molecular analyses have validated that these morphological grouping encompass distinct phylogenetic lineages $(42,44)$. However, molecular-based taxonomic structure within the small-spored Alternaria has proven to be quite complicated due to a lack of variability in markers commonly used in fungal systematics, especially for rDNA markers and protein coding genes $(5,23,42)$.

Corresponding author: B. M. Pryor; E-mail address: bmpryor@u.arizona.edu

* The $\boldsymbol{e}$-Xtra logo stands for "electronic extra" and indicates that the online version contains one supplemental figure and one supplemental table. Figure 1 appears in color online.

http://dx.doi.org/10.1094/PHYTO-04-12-0076-R

(C) 2012 The American Phytopathological Society
A restricted number of species within the small-spored alternata species-group, identified as pathotypes of A. alternata (Fries.) Keissler or as distinct species, are known to produce host-specific toxins (HST) $(31,56,66)$. The chemical structures of these toxins are well understood and these toxins function as distinct pathogenicity factors on a narrow range of cultivars within select host species. Akamatsu and collaborators found that the genes involved in the synthesis of these HSTs are contained in small conditionally dispensable chromosomes (2). Homologues for the HST synthesis have not been found in nonpathogenic strains of $A$. alternata isolates, initially suggesting that HST-producing taxa share a unique evolutionary history $(22,34,59)$. However, the involvement of horizontal gene transfer, initially only hypothesized but currently well accepted $(1,65)$, appears to have moved some of these genes among toxigenic taxa $(9,38,63)$.

A. mali Roberts was described in 1924 as the causal agent of the disease apple leaf blotch (48), which is very destructive on susceptible apple (Malus $\times$ domestica) cultivars $(51,52)$. Subsequent studies have revealed that Alternaria species pathogenic to apple, also referred to as apple pathotypes of A. alternata, are known to produce an HST, the AM toxin, which acts both on the functionality of the plant plasma membrane and the chloroplast $(24,27,36,40)$. Due to the HST production, these pathotypes cause severe defoliation and premature fruit drop on specific apple cultivars. The occurrence of $A$. mali has been a serious problem in Japan since 1970 (50) and in the United States since the late 1980s (17). Although apple leaf blotch severity in the United States may vary from year to year, there are strong indications that the causal agent has spread to new areas, such as North Carolina (53), Virginia, and West Virginia, and could become a problem in more northern areas of the midAtlantic region (16). In Europe, A. mali was reported in Yugo- 
slavia in 1996 and is among the quarantine pests of the European Union (12).

In 1999, a disease was reported among a number of apple tree orchards ('Golden Delicious') in the Trentino Alto Adige region of North Italy (Fig. 1) (32,33). By 2002, the disease had started infecting the Gala variety of apple and had expanded to an area approximately 10 times larger than the initial infection sites. At this time, it had been reported in the Veneto region, the Pidemont region, particularly near the cities of Cuneo and Alessandria, and some areas of the Emilia Romagna region, particularly near the cities of Ferrara and Ravenna (6,39). Symptoms usually appeared on leaves at the end of May as small circular brown spots of 2 to $5 \mathrm{~mm}$ diameter, increasing in number and coalescing during the following months. On fruits, spots (1 to $3 \mathrm{~mm})$ were often centered on the lenticels and were surrounded by a reddish halo, often resulting in light suberification. These spots were particularly visible during harvest time and postharvest storage, thus, damaging the marketability of afflicted fruits. Originally, the dis-

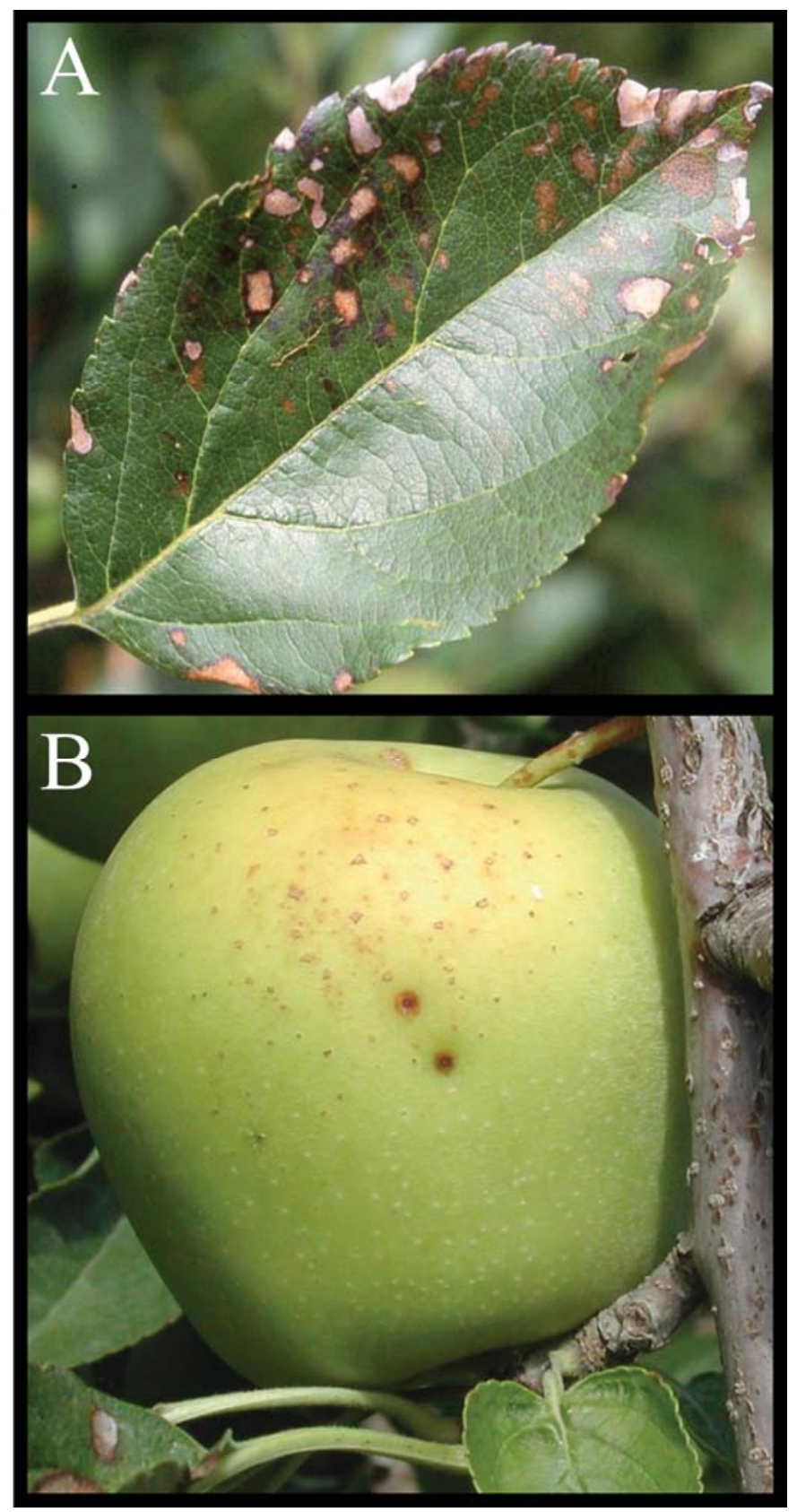

Fig. 1. Symptoms on $\mathbf{A}$, leaf and $\mathbf{B}$, fruit caused by Alternaria spp. in a 'Golden Delicious' apple orchard in northern Italy. ease was attributed to a lack of microelements or a nutritional disequilibrium (19). In 2003, the Laimburg Research Center for Agriculture and Forestry (Bolzano) hypothesized that the disease was caused by a pathotype of A. alternata $(19,32)$.

The purpose of this study was to characterize morphological and pathogenic diversity among isolates of small-spored Alternaria collected from apple in regions of Italy affected by a newly described Alternaria disease of apple. In addition, molecular differences among isolates were examined utilizing sequence analysis of specific loci (the endoPG gene and the three anonymous regions OPA1-3, OPA2-1, and OPA10-2) and DNA fingerprinting based upon inter simple sequence repeat markers (ISSR) and fragment length polymorphism (AFLP) markers. Finally, this study compared the morphological and molecular data sets to test the hypothesis that the pathogenic isolates belong to a single taxon, A. mali.

\section{MATERIALS AND METHODS}

Strain collection. Alternaria isolates were obtained from symptomatic tissues (leaves and fruits) from apple orchards in several geographical areas in northern Italy including Verona, Padova, Rovigo Trento, Bolzano, Udine, Pordenone, and Ravenna (Fig. 2). All material was received from extension service personnel working with farmers in affected apple orchards and collected between June and August 2007, 2008, and 2009. The cultivars most susceptible to infection were Early Gala and Golden Delicious. Included in this study were three Japanese strains of small-spored Alternaria pathogenic on apple: AKI-3 (Hirosaki University, = EGS 37-131; E. G. Simmons), IFO8984 (Institute of Fermentation, Osaka), and M71 (Tottori University), and the type isolate for A. mali (EGS 38-029), for comparative purposes $(2,51,56)$.

To obtain isolates, sections of tissue were excised from lesions on fruits and leaves using a sterile scalpel blade. Excised portions were dipped in $1 \%$ hypochlorite for $30 \mathrm{~s}$, washed with sterile water for $1 \mathrm{~min}$, and then placed on petri dishes containing potato dextrose agar (PDA) (Difco Laboratories, Detroit, MI). Dishes were incubated at $23^{\circ} \mathrm{C}$ with a photoperiod of $12 \mathrm{~h} \mathrm{light/dark}$. To confirm isolates as small-spored Alternaria, durable microscopy

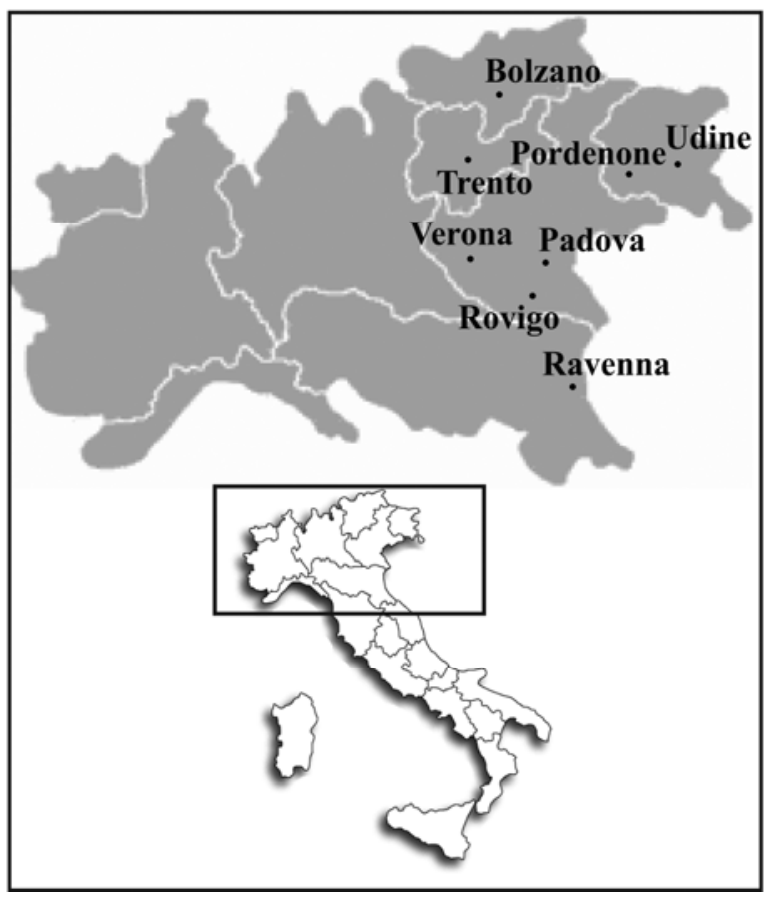

Fig. 2. Map of the geographical regions involved in this study. 
slides were prepared from 7-day-old cultures for examination of diagnostic conidium characteristics: catenulate ovoid spores with a tapering apical beak and transverse and longitudinal septa $(50,56)$. Positive Alternaria isolates were further compared with reference strains A. alternata (EGS 34-016), A. tenuissima (EGS 34-015), and A. arborescens (EGS 39-128), which correspond to three commonly occurring morphological groups based upon features of the three-dimensional sporulation apparatus. Based upon these comparisons, isolates were grouped into either the $A$. alternata morpho-group, the A. tenuissima morpho-group, or the $A$. arborescens morpho-group (46). All isolates were transferred to new PDA plates to obtain pure culture and then to PDA agar slants for storage at $4^{\circ} \mathrm{C}$.

Pathogenicity bioassays. All recovered Alternaria isolates were screened for pathogenicity on detached plant materials (fruits and leaves, wounded and unwounded) using the susceptible apple 'Golden Delicious'. Young leaves used for testing were collected from uniform genetic material grown in the greenhouses of the University of Bologna. Fruit used for testing were grown organically and obtained from cold storage facilities.

For wound assays, tissues on the lower side of the leaf or the upper part of the fruit were scratched slightly with a sterile blade. For each isolate, six drops $(15 \mu \mathrm{l} / \mathrm{drop}$ for leaf and $30 \mu \mathrm{l} / \mathrm{drop}$ for fruit) of conidial suspension $\left(10^{5}\right.$ conidia $\left./ \mathrm{ml}\right)$ were inoculated on the tissues (or wounds). Conidial suspensions were obtained by flushing 7-day-old colonies, grown on PDA, with sterile pure water and collecting resulting dislodged spores in suspension. Plant material was placed in plastic trays, covered with a plastic bag to maintain the humidity, and incubated at $23^{\circ} \mathrm{C}$. Disease symptom development was monitored for $72 \mathrm{~h}$.

For each pathogenicity screen, the development of necrosis was scored as presence or absence. All methods for testing pathogenicity were performed utilizing three replicates for each isolate. All isolates that tested positive in at least one of the initial pathogenicity screens were cultured again and single-spored cultures were obtained for further pathogenicity testing and morphological and molecular analysis.

Single-spored isolates were tested for pathogenicity using spore suspensions on wounded and unwounded leaves. In addition, single-spored isolates were also tested for the capability to produce extracellular toxins. One milliliter of conidial suspension was inoculated in $30 \mathrm{ml}$ of Czapek-Dox (Difco Laboratories) broth enriched with $0.5 \%$ yeast extract (Difco Laboratories) and incubated statically for 21 days at $23^{\circ} \mathrm{C}$. Following incubation, the culture broth was filtered with a $0.2 \mu \mathrm{m}$ filter (Millipore), and the filtrate was applied to wounded leaf material and incubated as mentioned above. An aliquot of the filtrate was also plated on PDA to check for the absence of viable fungus. Symptom development using both spores suspensions and culture filtrates was monitored daily for $72 \mathrm{~h}$ and evaluated by assigning a pathogenicity score. This score was assigned on the basis of the diameter of the necrotic area that developed $(1=$ no lesions, $2=$ $<2 \mathrm{~mm}, 3=2$ to $4 \mathrm{~mm}$, and $4=>4 \mathrm{~mm}$ ). For each strain inocu- lated, the pathogenicity score was obtained for each replicate by considering the median value of the six inoculations per leaf. Each leaf represented one replicate for the assay. The median pathogenicity scores among the three morpho-groups were subjected to a Kruskal-Wallis nonparametric test using PAST version 1.63 (21). The differences between the two treatments (wounded versus unwounded) were evaluated with a Mann-Whitney paired test.

Morphological characterization. For the subset of singlespored isolates, morphological characteristics of the colony and sporulation pattern were determined according to previous systematic work on Alternaria spp. $(23,46)$. Fungi were grown in triplicate on PDA plates and incubated at $22^{\circ} \mathrm{C}$ in darkness for 10 days. After incubation, cultures were examined for colony color, colony margin, colony texture, diameter, and the presence of pigments or crystals in the agar medium. Ridgway's color standards (47) and Nobles' descriptions of colony texture (37) were used to classify isolates and define phenological groups. The properties were visually evaluated or were measured and values were averaged.

To characterize isolates by sporulation habit, each isolate was cultured in triplicate on weak PDA (46) and incubated under controlled temperature $\left(22^{\circ} \mathrm{C}\right)$, humidity $(25 \%$ relative humidity), and lighting $\left(60 \mu \mathrm{moles} / \mathrm{m}^{2} / \mathrm{s}, 10: 14\right.$ light/dark cycle) in a programmable growth chamber (Conviron ATC 10-3, Conviron Controlled Environments, Pembina, ND) using the methodology described by Hong et al. (23). The three-dimensional sporulation apparatus was examined using a stereomicroscope at $40 \times$ magnification and morphology was scored on the basis of an 11-point coding system (chain length, presence of tapering beaked conidia, number of branches, and branching structure, Table 1) and values were averaged. All morphological studies were repeated once to confirm findings.

A matrix was created from the resulting morphological scores and analyzed with software PAST version 1.63 (21). Dendrograms were constructed using an unweighted paired group method of arithmetic means (UPGMA) algorithm based on the Euclidean distance. The sporulation characteristics of representative reference cultures were included in these analyses for comparative purposes.

Sequence analysis. For DNA extraction, mycelium was produced in $50 \mathrm{ml}$ of potato dextrose broth agitated on a rotary shaker at $120 \mathrm{rpm}$ for 14 days at $23^{\circ} \mathrm{C}$. This liquid culture was inoculated with $1 \mathrm{ml}$ of spore suspension $\left(10^{4}\right.$ conidia $\left./ \mathrm{ml}\right)$ obtained from 7-day-old PDA plates. Fungal mycelia were obtained from liquid culture by filtration through Miracloth and then lyophilized. DNA was extracted from lyophilized mycelia according to the methods of Pryor and Gilbertson (45). Following extraction, the DNA was resuspended in $200 \mu$ of TE $1 \times$ buffer, pH 8. Sample DNA concentration was measured on an ND 1000 spectrophotometer (NanoDrop Technologies, Wilmington, DE) and standardized to100 $\mathrm{ng} / \mu \mathrm{l}$.

Polymerase chain reaction (PCR) amplifications of specific genetic loci were carried out for all single spore isolates in a PTC-

TABLE 1. The 11-point morphological scoring system for characteristics of conidia and conidiophores

\begin{tabular}{|c|c|c|}
\hline & Characteristics of conidia and conidiophores & Scoring system \\
\hline A & $\%$ of sporulating structure (SS) containing at least one "tenuissima type" spore & $1: 0-2,2: 3-20,3: 21-79,4: 80-97,5: 98-100$ \\
\hline B & $\%$ of SS with subconidium conidiophore elongation & $1: 0-2,2: 3-20,3: 21-79,4: 80-97,5: 98-100$ \\
\hline $\mathrm{C}$ & Mode number of subconidium conidiophore elongations per positive SS & 1: no positive conidiophore, $2: 1,3: 2-4,4:>4$ \\
\hline $\mathrm{D}$ & Mode length of subconidium conidiophore elongations & $1:<1$ conidium length, $2: 1-2$ conidium length, $3:>2$ conidium length \\
\hline $\mathrm{E}$ & $\%$ of SS with lateral intraconidium conidiophore development & $1: 0-2,2: 3-20,3: 21-79,4: 80-97,5: 98-100$ \\
\hline $\mathrm{F}$ & Mode number of lateral intraconidium conidiophore development per positive SS & 1: no positive conidiophore, $2: 1,3: 2-4,4:>4$ \\
\hline $\mathrm{G}$ & Mode length of lateral intraconidium conidiophore development & $1:<1$ conidium length, $2: 1-2$ conidium length, $3:>2$ conidium length \\
\hline $\mathrm{H}$ & Mode length of longest chain per SS & $1: 1-4,2: 5-8,3: 9-14,4:>14$ \\
\hline I & $\%$ of SS with apical conidium terminus conidiophore development & $1: 0-2,2: 3-20,3: 21-79,4: 80-97,5: 98-100$ \\
\hline $\mathrm{J}$ & $\begin{array}{l}\text { Mode number of apical conidium terminus conidiophore development per } \\
\text { positive SS }\end{array}$ & 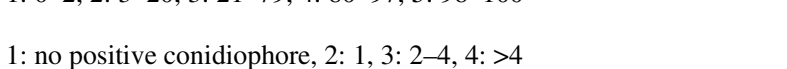 \\
\hline $\mathrm{K}$ & Mode length of apical conidium terminus conidiophore development & $1:<1$ conidium length, $2: 1-2$ conidium length, $3:>2$ conidium length \\
\hline
\end{tabular}


100 thermal cycler (Bio-Rad Laboratories Inc., Richmond, CA). The primers utilized were PG3/PG2b for the segment of endoPG gene, and OPA1-3L/OPA1-3R, OPA2-1L/OPA2-1R, and OPA102R/OPA10-2L for three anonymous regions. All four loci have been previously characterized and show to be useful in delimiting close phylogenic relationships among small-spored Alternaria spp. $(5,42)$. The reaction mixture $(25 \mu \mathrm{l})$ contained $20 \mathrm{ng}$ of DNA template, $0.2 \mu \mathrm{M}$ of each primers, $0.2 \mathrm{mM}$ PCR nucleotide mix, $2.5 \mu \mathrm{l}$ of $10 \times$ buffer (with $\mathrm{KCl}$ and $\left(\mathrm{NH}_{4}\right)_{2} \mathrm{SO}_{4}$ and $20 \mathrm{mM}$ $\mathrm{MgCl}_{2}$ ), and 1 unit of Taq polymerase (Fermentas DreamTaq, Fermentas Inc., Glen Burnie, MD). The cycling conditions were as follows: initial denaturation step at $94^{\circ} \mathrm{C}$ for 5 min followed by 35 cycles at $94^{\circ} \mathrm{C}$ for $45 \mathrm{~s}, \mathrm{~T}^{\circ} \mathrm{C}$ annealing temperature $\left(\mathrm{T}^{\circ} \mathrm{C}=56\right.$ for endoPG primers, $\mathrm{T}^{\circ} \mathrm{C}=60$ for OPA $10-2$ primers, $\mathrm{T}^{\circ} \mathrm{C}=58$ for OPA $1-3$ and OPA2-1 primers) for $45 \mathrm{~s}$, and $72^{\circ} \mathrm{C}$ for $45 \mathrm{~s}$. These cycles were followed by a final extension step at $72^{\circ} \mathrm{C}$ for $7 \mathrm{~min}$.

Successful PCR amplifications were visualized on $1.2 \%$ agarose gel using ethidium bromide staining. Prior to sequencing, $16 \mu \mathrm{l}$ of PCR product was purified using the combination of shrimp alkaline phosphatase (1 unit, Roche Applied Science, Indianapolis, IN) and exonuclease I (0.3 unit, US Biochemical, Cleveland, $\mathrm{OH}$ ) in a final reaction volume of $20 \mu \mathrm{l}$. Amplicons were then submitted to the University of Arizona Genetics Core at the Arizona Research Laboratories for bidirectional sequencing performed with ABI BigDye Terminator Cycle Sequencing Kit (Applied Biosystem, Foster City, CA) in an ABI PRISM 3100 automated sequencer. Resulting sequences were trimmed and edited using the Bioedit software version 7.05 (20) before further analysis. Initial sequence alignments for phylogenetic analysis were completed using ClustalW version 2.0.12 and manually adjusted using Mesquite software version $2.72(29,61)$ and MacClade phylogenetic software (28).

Heuristic maximum parsimony trees were constructed for each marker of interest (endoPG, OPA1-3, OPA2-1, and OPA10-2) using PAUP version 4.0 beta (58). For each search, sequence addition was set to random with 1,000 repetitions and the rest of the settings were default. A full heuristic bootstrap search with 1,000 random sequence additions and 1,000 bootstrap replicates was conducted for each tree to obtain support values. These values were then mapped onto a majority rule consensus tree of the most parsimonious trees. In addition, a concatenated data set was constructed from the four loci and analyzed similarly.

AFLP analysis. AFLP analysis was conducted following the method described in Vos et al. (64), except that the profiles were obtained using polyacrylamide gel electrophoresis and visualized through silver staining. Genomic DNA (250 ng) was digested for
$2 \mathrm{~h}$ at $37^{\circ} \mathrm{C}$ with $5 \mathrm{U}$ of the frequent cutter enzyme TruI (isoschizomer of MseI, Fermentas Inc.) and $5 \mathrm{U}$ of the rare cutter enzyme EcoRI (Fermentas Inc.) in $50 \mu \mathrm{l}$ of restriction/ligase $(\mathrm{R} / \mathrm{L})$ buffer $5 \times(50 \mathrm{mM}$ Tris-Cl, $\mathrm{pH} 7.5,50 \mathrm{mM} \mathrm{Mg}$-acetate, and $250 \mathrm{mM}$ K-acetate). Adaptors (Eco-F: 5'-CTCGTAGACT GCGTACC-3', Eco-R: 5'-AATTGGTACGCAGTCTAC-3'; MseF: 5'-GACGATGAGTCCTGAG-3', Mse-R: 5'-TACTCAGGAC TCAT $\left.-3^{\prime}\right)$ were ligated at $37^{\circ} \mathrm{C}$ for $3 \mathrm{~h}$, combining $10 \mu \mathrm{l}$ of ligation solution (5 pmol ADA-EcoRI 5, 50 pmol ADA-TruI, $0.2 \mathrm{mM}$ ATP, $1 \mathrm{U}$ of ligase, and $2 \mu \mathrm{l}$ of R/L buffer $5 \times$ ) with $40 \mu \mathrm{l}$ of digestion product. The pre-amplification was carried out by adding to $5 \mu \mathrm{l}$ of $1 / 10$ diluted ligation product $2.0 \mu \mathrm{l}$ of buffer $10 \times$ (100 mM Tris- $\mathrm{HCl}, \mathrm{pH} 8.3$, and $500 \mathrm{mM} \mathrm{KCl}$ ), $2 \mu \mathrm{l}$ of $\mathrm{MgCl}_{2}$, $15 \mathrm{mM}, 0.16 \mu \mathrm{l}$ of dNTPs $25 \mathrm{mM}$ each, $1 \mathrm{U}$ of Taq polymerase, and $1.6 \mu \mathrm{l}$ of nonselective primers combination $(50 \mathrm{ng} / \mu \mathrm{l}$ each of MseI-0 and EcoRI-0) in a final volume of $20 \mu \mathrm{l}$. Cycling conditions were set as a denaturation step of $1 \mathrm{~min}$ at $94^{\circ} \mathrm{C}$ followed by 40 cycles $\left(94^{\circ} \mathrm{C}\right.$ for $30 \mathrm{~s}, 55^{\circ} \mathrm{C}$ for $30 \mathrm{~s}, 72^{\circ} \mathrm{C}$ for $\left.1 \mathrm{~min}\right)$. Amplicons were visualized on a $2 \%$ agarose gel as faint smears of DNA. A pre-amplification 1:50 dilution was used to carry out selective PCR performed in a $20-\mu \mathrm{l}$ reaction volume using different primers combinations, selected on the basis of previous works $(14,18)$. MseI, EcoRI with two selective nucleotide at the $3^{\prime}$ end (Table 2), and the same Master Mix composition were employed in the selective PCR reaction. The PCR cycle was edited in the following initial denaturing step at $94^{\circ} \mathrm{C}$ for 1 min followed by 40 cycles of $94^{\circ} \mathrm{C}$ for $1 \mathrm{~min}, 62^{\circ} \mathrm{C}$ for $30 \mathrm{~s}$, and $72^{\circ} \mathrm{C}$ for $1 \mathrm{~min}$. Each reaction was performed twice. Products were visualized via electrophoresis in $4.5 \%$ (wt/vol) acrylamide gel in $1 \times \mathrm{TBE}$ buffer by staining with silver nitrate technique (7). The size of the DNA fragments was estimated by comparing the DNA bands with a 100-bp GeneRuler DNA ladder (Fermentas Inc.).

ISSR analysis. A set of ISSRs primers were selected to analyze the genetic diversity within the population of Italian isolates. Of 11 ISSR primers screened, nine provided suitable for this study and gave a polymorphic reproducible pattern (Table 2). PCRs were performed on the basis of other fingerprinting research, with minor modifications $(62,67)$. PCRs were carried out in a final volume of $25 \mu \mathrm{l}$ containing $20 \mathrm{ng}$ of DNA template, $0.7 \mu \mathrm{M}$ of primer, $0.2 \mathrm{mM}$ PCR nucleotide mix, $2.5 \mu \mathrm{l}$ of $10 \times \mathrm{Taq}$ buffer (with $\mathrm{KCl}$ and $\left(\mathrm{NH}_{4}\right)_{2} \mathrm{SO}_{4}$ and $20 \mathrm{mM} \mathrm{MgCl}_{2}$ ), and 1 unit of Taq polymerase (DreamTaq, Fermentas Inc.). DNA amplification was performed in a PTC-100 thermal cycler with an initial denaturing step at $94^{\circ} \mathrm{C}$ for $5 \mathrm{~min}$, followed by 35 cycles at $94^{\circ} \mathrm{C}$ for $1 \mathrm{~min}, 48^{\circ} \mathrm{C}$ for $75 \mathrm{~s}$, and $72^{\circ} \mathrm{C}$ for $2 \mathrm{~min}$ and a final extension cycle at $72^{\circ} \mathrm{C}$ for $7 \mathrm{~min}$. The annealing temperature was adapted

TABLE 2. Molecular data for each amplified fragment length polymorphism (AFLP) primer combination and inter simple sequence repeat (ISSR) primer

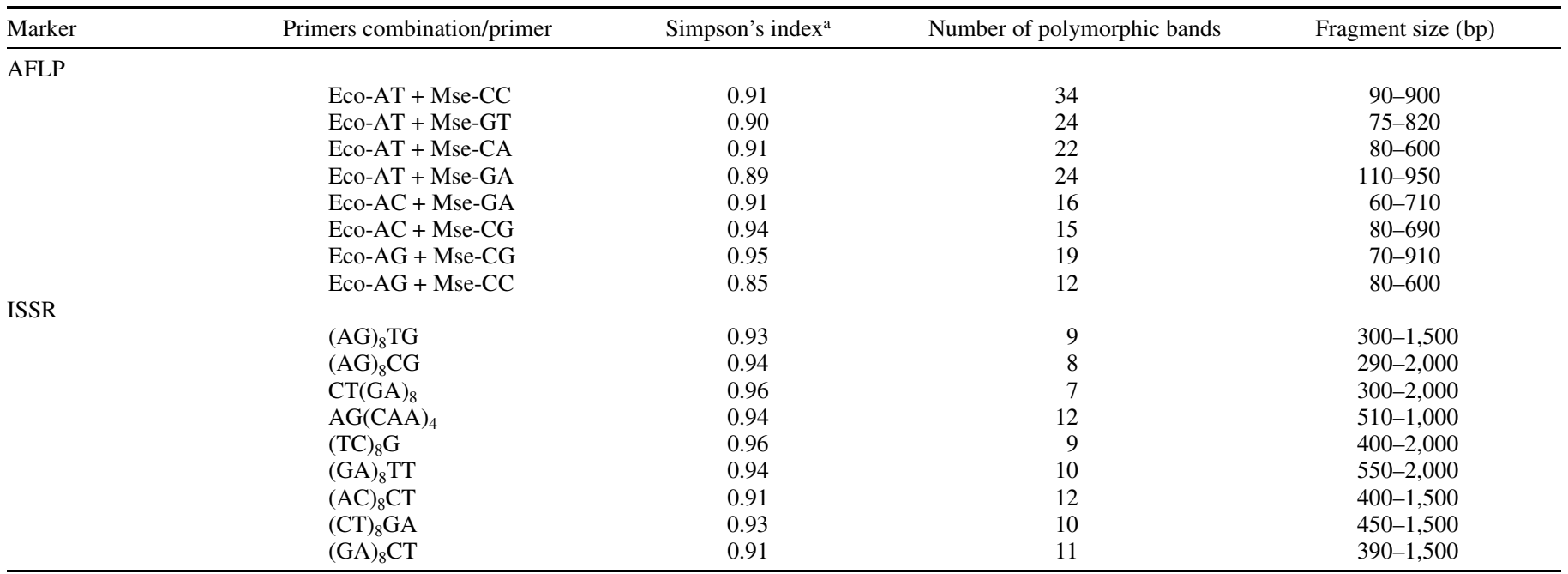

a Simpson's index $S_{i}=\Sigma 1-\Sigma p_{i}^{2} / n$, where $p_{i}$ is the frequency of the allele $i$ th and $n$ is the number of the detected loci for each primer combination/primer. 
on the bases of the specific annealing temperature of the primer used (Table 2). Each reaction was performed twice. Products were subjected to electrophoresis in a $1.2 \%(\mathrm{wt} / \mathrm{vol})$ agarose gel in $0.5 \times$ TBE buffer and visualized under UV light by staining in ethidium bromide. The size of the DNA fragments was estimated by comparing the DNA bands with a 1-kb GeneRuler DNA ladder (Fermentas, Inc.). Images were captured using the software LabWorks 4.0, UVP Bioimaging System, in a Epichemi3 Darkroom (UVP, Upland, CA).

Statistical analysis. The fingerprinting profiles were analyzed with QuantityOne version 4.2.1 software (Bio-Rad). Only those bands that showed consistent and unambiguous amplification were scored. Smeared and weak bands were excluded. Amplified fragments were scored as discrete variables using 1 to indicate presence and 0 for absence of the bands. The resulting banding profile scores were used to construct two binary qualitative data matrices by UPGMA utilizing PAST software version 1.63. Dice's coefficients (13) were used to establish the similarities among the isolates and constitute discrete clusters. The polymorphic information content (PIC) for each amplicon (locus) was calculated and defined as PIC $=1-\Sigma p_{i}{ }^{2}$, where $p$ represent the frequencies of the allele $i$ for the locus investigated. Loci with a low PIC value $(<0.25)$ were excluded. The discriminatory power of each primer (or primer combination) was assessed with the Simpson's diversity index (57), and calculating the percentage of the polymorphic bands, using the software PAST version 1.63. The correlation between the two matrices generated by the fingerprinting profiles was estimated using the Mantel test (30), conducted in this study with the program PAST version 1.63. In order to assess the molecular diversity within the Alternaria single-spored strains an analysis of molecular variance (AMOVA) was performed (15). The analysis was carried out separately for AFLP and ISSR data sets calculating the partitioning of the genetic variation among the populations, defined by the cluster analysis. The estimation of the differentiation $\left(\Phi_{\mathrm{T}}\right.$ and the Nei genetic distance (D) (35) were computed using the software GenAlEx version 6.3 (41).

A principal component analysis (PCA) was performed to further examine the relationships among the geographic origin, pathogenicity scores, and molecular markers of the isolates (26). The PCA was conducted in this study using the program PAST version 1.63. Association between pathogenicity and each locus was evaluated with the Pearson $\chi^{2}$ statistic test and Fischer exact statistic test. Benjamini and Hochberg's false discovery rate (FDR) was used to adjust $P$ values for multiple tests (8).

A. mali toxin gene-specific PCR. The single-spored isolates were examined utilizing specific primers designed by Johnson et al. (25) to detect the AM toxin gene and elucidate if the pathogenicity was linked to the presence of this gene. PCR was carried out following the cited work with minor modifications. The reaction mixture $(25 \mu \mathrm{l})$ contained $20 \mathrm{ng}$ of genomic DNA template, $1 \mu \mathrm{M}$ of each primers, $0.2 \mathrm{mM}$ of PCR nucleotide mix, $1 \times$ buffer with $\mathrm{KCl}$ and $\left(\mathrm{NH}_{4}\right)_{2} \mathrm{SO}_{4}, 1.2 \mathrm{mM} \mathrm{MgCl}_{2}$, and 1 unit of Taq polymerase (Takara Bio Inc., Tokyo, Japan). The cycling conditions were as follows: initial denaturation step at $94^{\circ} \mathrm{C}$ for 5 min followed by 35 cycles of $94^{\circ} \mathrm{C}$ for $45 \mathrm{~s}, 65^{\circ} \mathrm{C}$ of annealing temperature for $45 \mathrm{~s}$, and $72^{\circ} \mathrm{C}$ for $45 \mathrm{~s}$. These cycles were followed by a final extension step at $72^{\circ} \mathrm{C}$ for $7 \mathrm{~min}$. Positive controls to check the DNA quality were performed using primers for the glyceraldehyde dehydrogenase gene GPD1 and GPD2 (10). Products were visualized as previously described on a $1.2 \%$ agarose gel, stained with ethidium bromide, and scored as present or absent. PCRs were performed several times changing parameters that would have affected the appearance of the bands so to reduce the probability of false positives or negatives.

Positive PCRs were purified using the Sigma Genosys Cleanup kit (Sigma-Genosys Ltd., UK) and sequenced in both direction by BMR Genomics Sequencing Service, University of Padua, Italy (http://www.bmr-genomics.it). Chromatograms were checked and trimmed manually using the Bioedit software version 7.05. The sequences retrieved were compared with those available in the online database provided by the National Center for Biotechnology Information (NCBI) using the Blast search program. Alignment with the sequences of the AM-toxin gene, deposited in NCBI, was performed using Mesquite software. To investigate the flanking region of the specific AM-toxin amplicon, other primer pairs were designed downstream and upstream of the original primer sites (AMtox F1 CTGACTGGCCAGGCGGCTTG, AMtox R1 GCATATGCGGCGACACGAG, AMtox F2 GCTGC TTGTCATTCAGCCTCC, and AMtox R2 GGCGAGTATCCTC TCATGCCG). PCR analyses using the new primer pairs were carried out on all samples that had positive results in the first specific PCR without changing parameters of the master mix composition or the PCR cycle condition, with the exception of the annealing temperature.

\section{RESULTS}

Strain collection and pathogenicity bioassays. The collection of isolates recovered from apple consisted of a total of 173 isolates, 65 of which were collected from leaf lesions and 108 from fruit lesions. Initial pathogenicity screening revealed 44 isolates that produced necrosis on either fruit or leaf. Interestingly, the ability to produce symptoms was not uniform as $70 \%$ of the isolates were able to produce necrosis on both wounded leaves and wounded fruit while only $30 \%$ were able to induce necrosis on unwounded leaves and $5 \%$ on unwounded fruit.

Bioassays on leaf tissue proved to be the most reproducible with unambiguous symptoms, so this assay was chosen to repeat for the 44 single-spored isolates. The results for the spore suspension bioassays on leaf material mirrored the trend of the initial screen performed with symptoms induced by $83 \%$ of the isolates on wounded tissues and by $35 \%$ on unwounded tissues. For each type of inoculation, the median pathogenicity scores were calculated for each morpho-group. High variability of pathogenicity score was found within each group according to the Kruskal-Wallis comparison, which did not show statistically significant differences $(P>0.05)$ (Table 3$)$. Differences between the two kinds of treatments (wounded/unwounded) were statistically significant according to the Mann-Whitney paired test $(P<$ 0.05) (Fig. 3A). The inoculation of the filtrate induced symptoms for $42 \%$ of tested strains and there were no differences in pathogenicity score among the morpho-groups for this assay (Fig. 3B). Pathogenicity scores were variable among isolates from the different geographic regions with no obvious associations (data not shown).

Morphological characterization of single-spored isolates. The characterization of the colony morphology delineated three major groups referred to as the alternata, tenuissima, and arborescens morpho-groups (Supplemental Table 1), which have been described in previous studies of phytopathogenic Alternaria $(23,46)$. The alternata morpho-group $(n=4)$ produced colonies that were usually green (from deep olive gray to olivaceous black), had a smooth margin and a white border (2 to $4 \mathrm{~mm}$ ), and had a colony textures ranging from felty to woolly. After 10 days of growing in the darkness, the diameter of these isolates typically exceeded $70 \mathrm{~mm}$ and crystals in the agar medium underneath the mycelial mat were usually observed. The tenuissima morphogroup $(n=27)$ produced colonies that were pale olive gray to dark olive gray, often with thin white margins. These were characterized by a high growth rate $(>60 \mathrm{~mm})$ and the production of crystals underneath the mycelia mat. Colony texture ranged from woolly to cottony. The arborescence morpho-group $(n=13)$ produced dark colonies (pale olive gray to olivaceous black) with wavy torn borders and felty to woolly texture. The production of crystals was observed in the agar medium underneath the mycelia 
mat, as was a pale orange diffusible pigment in the medium. After 10 days of growing in darkness, the growth of individuals in this group never exceeded a diameter of $50 \mathrm{~mm}$, as is typical of $A$. arborescens. A. alternata f. sp. mali pathotype reference isolates showed different grades of texture and color but most resembled the tenuissima species-group (Supplemental Figure 1).

Three main groups were also distinguished based upon sporulation pattern and comparisons with the reference isolates for the alternata morpho-group, the tenuissima morpho-group, and the arborescens morpho-group. The alternata morpho-group $(n=4)$ was distinguished by primary conidium chains of 6 to 12 spores in length with secondary branches (two to six conidia) growing from terminal, median or basal conidium cells, and a rarity of tertiary branches. One strain (25FrA) was unusual in that the colony morphology fit within the alternata morpho-group, but its sporulation was characterized by the absence of intra-conidium conidiophore development as in the arborescens morpho-group. The tenuissima group $(n=21)$ formed long linear chains ( 6 to 15 conidia long), and when branching, it was observed that they never exceeded two to three conidia in length. The arborescens group $(n=10)$ was characterized by short conidia chains, primary conidiophores of two to eight conidia in length, and secondary conidiophores always originating from distal cells (usually three to five per conidiophore). Moreover, tertiary and quaternary branching was observed throughout the highly geniculate sporulation structure.

Seven isolates (4Fr, 6FgA, 11Bz1, 11Bz4, A138, A152, and F09) were not scored for sporulation because spores were absent or too scarce to be able to ascribe to any of the three morphogroups even after repeated attempts to increase sporulation by changing growth conditions and using different media culture. Three of the reference strains of A. alternata f. sp. mali pathotype

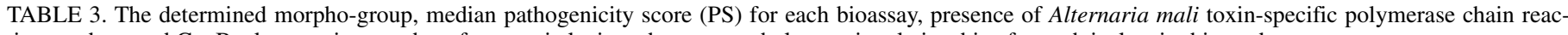
tion product, and GenBank accession numbers for genetic loci used to assess phylogenetic relationships for each isolate in this study

\begin{tabular}{|c|c|c|c|c|c|c|c|c|c|}
\hline \multirow[b]{2}{*}{ Strain code } & \multirow[b]{2}{*}{ Morpho-group } & \multirow{2}{*}{$\begin{array}{l}\text { PS spore suspension } \\
\text { on wounded leaf }\end{array}$} & \multirow{2}{*}{$\begin{array}{l}\text { PS spore suspension } \\
\text { on unwounded leaf }\end{array}$} & \multirow{2}{*}{$\begin{array}{l}\text { PS filtrate on } \\
\text { wounded leaf }\end{array}$} & \multirow{2}{*}{$\begin{array}{l}\text { AM- } \\
\text { toxin }\end{array}$} & \multicolumn{4}{|c|}{ GenBank accession numbers } \\
\hline & & & & & & EndoPG & OPA1-3 & OPA2-1 & OPA10-2 \\
\hline 1FrA & A. tenuissima & 1 & 1 & 1 & No & JQ800479 & JQ800527 & JQ800623 & JQ800575 \\
\hline $2 \mathrm{FrA}$ & A. tenuissima & 3 & 1 & 1 & No & JQ800480 & JQ800528 & JQ800624 & JQ800576 \\
\hline $2 \mathrm{FrC} 08$ & A. tenuissima & 2 & 2 & 3 & Yes & JQ800481 & JQ800529 & JQ800625 & JQ800577 \\
\hline $4 \mathrm{BZ}$ & A. tenuissima & 1 & 1 & 1 & No & JQ800482 & JQ800530 & JQ800626 & JQ800578 \\
\hline $4 \mathrm{Fr}$ & A. tenuissima & 1 & 1 & 1 & No & JQ800483 & JQ800531 & JQ800627 & JQ800579 \\
\hline $6 \mathrm{FgA}$ & A. tenuissima & 3 & 1 & 4 & No & JQ800484 & JQ800532 & JQ800628 & JQ800580 \\
\hline 8FgA08 & A. tenuissima & 1 & 1 & 1 & No & JQ800485 & JQ800533 & JQ800629 & JQ800581 \\
\hline 8FgB08 & A. tenuissima & 3 & 2 & 1 & Yes & JQ800486 & JQ800534 & JQ800630 & JQ800582 \\
\hline $8 \mathrm{FgC0} 8$ & A. tenuissima & 3 & 2 & 3 & No & JQ800487 & JQ800535 & JQ800631 & JQ800583 \\
\hline 8 FrC08 & A. tenuissima & 3 & 1 & 1 & No & JQ800488 & JQ800536 & JQ800632 & JQ800584 \\
\hline $9 \mathrm{BZ}$ & A. tenuissima & 3 & 3 & 4 & No & JQ800491 & JQ800539 & JQ800635 & JQ800585 \\
\hline 9FrC & A. tenuissima & 2 & 1 & 1 & No & JQ800490 & JQ800538 & JQ800634 & JQ800587 \\
\hline 9FgB & A. arborescens & 3 & 2 & 3 & No & JQ800489 & JQ800537 & JQ800633 & JQ800586 \\
\hline $10 \mathrm{FgB}$ & A. arborescens & 3 & 2 & 2 & Yes & JQ800492 & JQ800540 & JQ800636 & JQ800590 \\
\hline 10BZ2 & A. arborescens & 1 & 2 & 1 & No & JQ800493 & JQ800541 & JQ800637 & JQ800588 \\
\hline 10BZ3 & A. arborescens & 2 & 2 & 1 & No & JQ800494 & JQ800542 & JQ800638 & JQ800589 \\
\hline 11BZ1 & A. arborescens & 1 & 1 & 1 & No & JQ800495 & JQ800543 & JQ800639 & JQ800591 \\
\hline 11BZ4 & A. arborescens & 1 & 1 & 1 & No & JQ800496 & JQ800544 & JQ800640 & JQ800592 \\
\hline $14 \mathrm{Fg}$ & A. arborescens & 1 & 1 & 1 & No & JQ800497 & JQ800545 & JQ800641 & JQ800593 \\
\hline $14 \mathrm{FgD}$ & A. tenuissima & 3 & 1 & 3 & Yes & JQ800498 & JQ800546 & JQ800642 & JQ800594 \\
\hline $14 \mathrm{FrA}$ & A. tenuissima & 2 & 1 & 1 & No & JQ800499 & JQ800547 & JQ800643 & JQ800595 \\
\hline $18 \mathrm{Fg}$ & A. arborescens & 3 & 1 & 1 & No & JQ800500 & JQ800548 & JQ800644 & JQ800596 \\
\hline $18 \mathrm{Fr}$ & A. tenuissima & 4 & 2 & 4 & No & JQ800501 & JQ800549 & JQ800645 & JQ800597 \\
\hline $19 \mathrm{FrC}$ & A. tenuissima & 3 & 1 & 1 & No & JQ800502 & JQ800550 & JQ800646 & JQ800598 \\
\hline $20 \mathrm{FgB}$ & A. tenuissima & 2 & 2 & 4 & No & JQ800503 & JQ800551 & JQ800647 & JQ800599 \\
\hline $21 \mathrm{FgB}$ & A. alternata & 3 & 2 & 2 & No & JQ800504 & JQ800552 & JQ800648 & JQ800600 \\
\hline $24 \mathrm{FgB}$ & A. arborescens & 3 & 1 & 1 & No & JQ800505 & JQ800553 & JQ800649 & JQ800601 \\
\hline $25 \mathrm{FgB}$ & A. arborescens & 3 & 1 & 1 & No & JQ800506 & JQ800554 & JQ800650 & JQ800602 \\
\hline $25 \mathrm{FrA}$ & A. alternata & 2 & 3 & 4 & No & JQ800507 & JQ800555 & JQ800651 & JQ800603 \\
\hline $26 \mathrm{FgA}$ & A. arborescens & 3 & 2 & 4 & No & JQ800508 & JQ800556 & JQ800652 & JQ800604 \\
\hline $28 \mathrm{FgD}$ & A. alternata & 3 & 1 & 1 & No & JQ800509 & JQ800557 & JQ800653 & JQ800605 \\
\hline $36 \mathrm{Fg}$ & A. alternata & 3 & 1 & 1 & No & JQ800510 & JQ800558 & JQ800654 & JQ800606 \\
\hline 37FrA & A. tenuissima & 2 & 1 & 3 & No & JQ800511 & JQ800559 & JQ800655 & JQ800607 \\
\hline 37FrB & A. arborescens & 3 & 1 & 3 & No & JQ800513 & JQ800561 & JQ800656 & JQ800608 \\
\hline $37 \mathrm{FrC}$ & A. tenuissima & 3 & 1 & 1 & No & JQ800512 & JQ800560 & JQ800657 & JQ800609 \\
\hline 37Biol & A. arborescens & 3 & 3 & 1 & No & JQ800514 & JQ800563 & JQ800658 & JQ800610 \\
\hline 37Test & A. tenuissima & 2 & 2 & 2 & No & JQ800515 & JQ800562 & JQ800659 & JQ800611 \\
\hline 39FrB & A. tenuissima & 1 & 1 & 1 & No & JQ800516 & JQ800564 & JQ800660 & JQ800612 \\
\hline 39FrC & A. tenuissima & 1 & 1 & 1 & No & JQ800517 & JQ800565 & JQ800661 & JQ800613 \\
\hline A138 & A. tenuissima & 3 & 3 & 3 & Yes & JQ800518 & JQ800566 & JQ800662 & JQ800614 \\
\hline A152 & A. tenuissima & 3 & 3 & 3 & Yes & JQ800519 & JQ800567 & JQ800663 & JQ800615 \\
\hline \multirow[t]{2}{*}{ B19 } & A. tenuissimal & & & & & & & & \\
\hline & A. arborescens & 3 & 3 & 4 & Yes & JQ800520 & JQ800568 & JQ800664 & JQ800616 \\
\hline B50 & A. tenuissima & 3 & 1 & 3 & No & JQ800521 & JQ800569 & JQ800665 & JQ800617 \\
\hline F09 & A. tenuissima & 2 & 1 & 1 & No & JQ800522 & JQ800570 & JQ800666 & JQ800618 \\
\hline EGS37-131 & A. tenuissima & 3 & 3 & 3 & Yes & JQ800523 & JQ800571 & JQ800667 & JQ800619 \\
\hline EGS38-029 & A. tenuissima & 2 & 1 & 1 & No & JQ800524 & JQ800572 & JQ800668 & JQ800620 \\
\hline IFO8984 & A. tenuissima & 3 & 3 & 3 & Yes & JQ800525 & JQ800573 & JQ800669 & JQ800621 \\
\hline \multirow[t]{2}{*}{ M71 } & A. tenuissimal & & & & & & & & \\
\hline & A. arborescens & 3 & 3 & 3 & Yes & JQ800526 & JQ800574 & JQ800670 & JQ800622 \\
\hline EGS34-016 & A. alternata & Not tested & Not tested & Not tested & No & JQ859822 & JQ859819 & JQ859825 & JQ859828 \\
\hline EGS34-015 & A. tenuissima & Not tested & Not tested & Not tested & No & JQ859823 & JQ859820 & JQ859826 & JQ859829 \\
\hline EGS39-128 & A. arborescens & Not tested & Not tested & Not tested & No & JQ859824 & JQ859821 & JQ859827 & JQ859830 \\
\hline
\end{tabular}


(EGS 37-131, IFO8984, and EGS 38-029) exhibited sporulation habits typical of the tenuissima morpho-species group, while the M71 reference strain was characterized by an arborescens sporulation pattern. The scoring of sporulation characters was interpreted with a cluster analysis (Fig. 4) that clearly shows distinct clusters that coincide with colony morphology clusters, with the exception of isolate 25FrA that clustered with the arborescens morpho-group instead of the alternata morpho-group. Moreover, the pathogenicity score given to each single spore isolate seemed to highlight the capability of the strains to produce putative toxins independently of belonging to a morpho-species group.

Phylogeny and parsimony analysis. PCR successfully amplified the expected products from all isolates for the four targeted loci. endoPG, OPA1-3, OPA2-1, and OPA10-2 primers yielded amplicons averaging 389, 780, 520, and $620 \mathrm{bp}$, respectively. The endoPG sequence alignment showed seven informative sites and only one most parsimonious tree (tree length $=7$ ) with a consis-
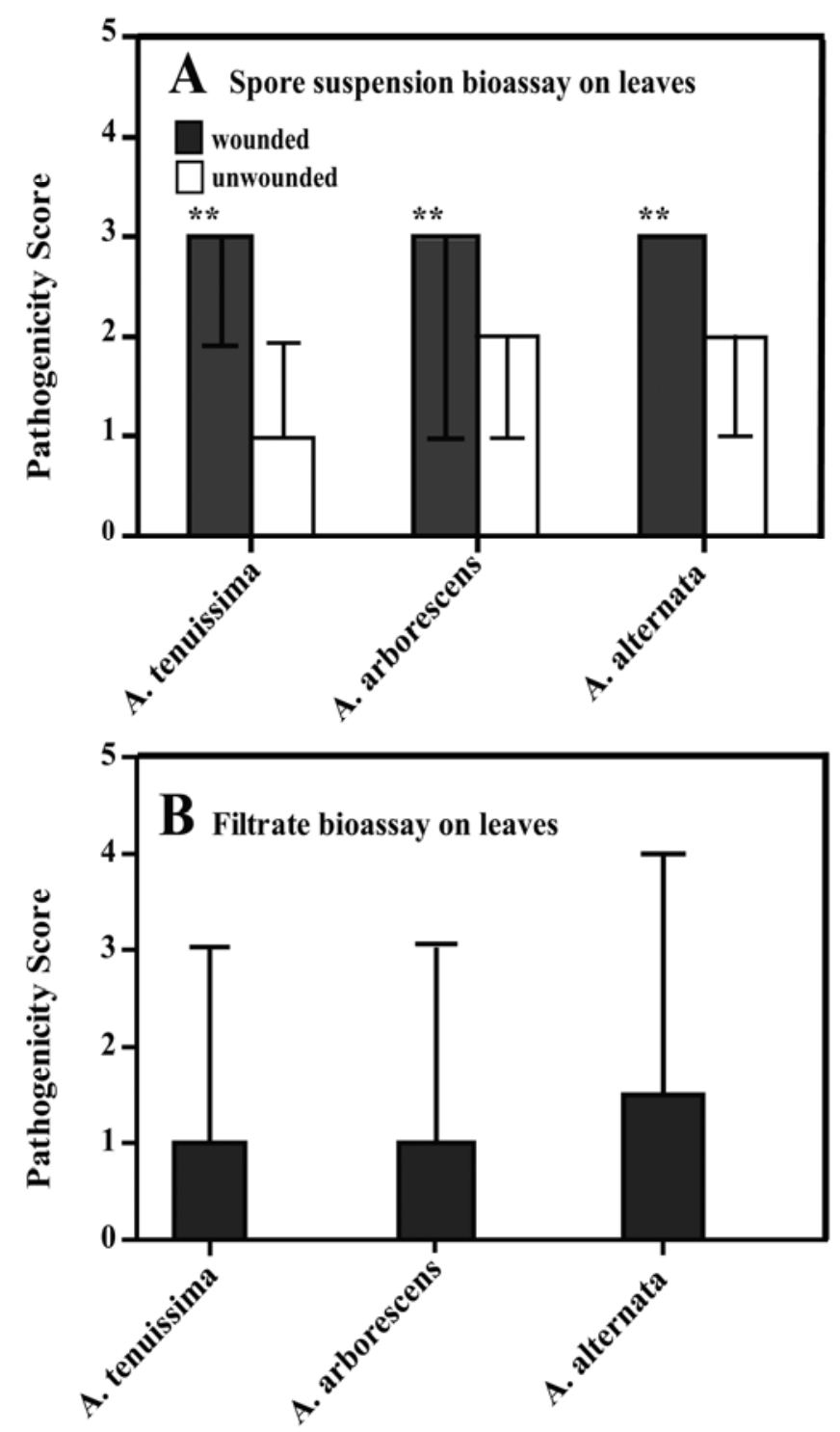

Fig. 3. Median pathogenicity scores from the leaf bioassay are reported for the single-spored isolates belonging to one of the three morpho-groups: $\mathbf{A}$, Spore suspension $\left(10^{5}\right.$ conidia/ml $)$ test and $\mathbf{B}$, filtrate test. Pathogenicity score was assigned to each isolate on the basis of the diameter of lesions developed following the rating scale: $1=$ no lesions, $2=<2 \mathrm{~mm}, 3=2$ to $4 \mathrm{~mm}$, and $4=$ $>4 \mathrm{~mm}$. Differences in pathogenicity score, resulting from two types of treatment (wounded and unwounded), were significant according to a MannWhitney paired test $(* *$ indicates $P<0.05)$. Bars represent the interquartile range. tency index (C.I.) equal to 1 and a retention index (R.I.) equal to 1. The OPA1-3 region showed 85 informative sites which produced 24 equally parsimonious trees (tree length $=121$ ) with C.I. $=0.82$ and R.I. = 0.97. The OPA2-1 sequence alignment showed 17 informative characters and yielded 31 equally parsimonious trees (tree length $=12$ ) with C.I. $=0.92$ and R.I. $=0.98$. The OPA10-2 sequence alignment showed 47 informative characters and yielded 415 equally parsimonious trees (tree length $=86$ ) with C.I. $=0.63$ and R.I. $=0.95$. For all loci examined, the arborescens morphogroup clustered with the representative culture of $A$. arborescens with $>70 \%$ bootstrap support, with the exception of strain 25FrA, which clearly revealed sequences of the alternata/tenuissima morpho-group but had sporulation morphology of the arborescens group. However, the alternata and tenuissima morpho-groups were never distinguished from each other as separate unmixed clades. Similarly, in the concatenated tree (tree length $=374)$ (Fig. 5 ), the arborescens morpho-group was resolved as monophyletic clade with $86 \%$ bootstrap support (clade 3), but the alternata and tenuissima morpho-groups remained unresolved with strains corresponding to both groups distributed among two poorly supported clades 1 and 2 (bootstrap support $=80$ ).

AFLP and ISSR analysis. The eight primer combinations utilized in the AFLPs analysis produced a total of 166 polymorphic bands and the size of amplification products ranged between 70 to $950 \mathrm{bp}$. The number of polymorphic fragments per each couple utilized was 12 to 34 with an average of 25 bands per combination. The Simpson's index (S) calculated to assess the discriminatory power of each primers combination ranged from 0.85 to 0.95 (Table 2).

A total of 95 polymorphic bands were produced using the nine ISSRs primers and the size of the amplification products ranged from 290 to 1,500 bp. Each primer generated 7 to 12 bands with an average of 10 bands per primer. The Simpson's index calculated for each set of data ranged from 0.91 to 0.96 (Table 2). The PIC was estimated for each locus, and those loci with a value lower than 0.25 were not included in the subsequent cluster and principal component analyses (10 loci for AFLP and 7 loci for ISSR).

Data analysis. Trees obtained for the two data sets, analyzed with UPGMA based on Dice's similarity index, were able to discriminate the arborescens morph-group as a well-defined cluster (Fig. 6). The correlation between the two matrices estimated with the Mantel test gave a value of $r=0.82(5,000$ random permutations and $P>0.05$ ), showing strong concordance of results obtained with the two different techniques. The clusters defined by the ISSR profiles revealed that the percentage of bands that were polymorphic in the arborescens groups was $89.8 \%$ and the percentage for the alternata-tenuissima group was $95.4 \%$. The AFLP analysis split the non-arborescens isolates into two clusters: an alternata-tenuissima cluster and a tenuissima cluster. For each cluster defined by the AFLP analyses, the percentage of polymorphic bands was $92.2,63.1$, and $84.4 \%$ for the alternatatenuissima group, the tenuissima group, and the arborescens group, respectively. The AMOVA, performed on the two data sets showed that the molecular variance was higher within the groups than among them $(61 \%$ versus $39 \%$ for the ISSR data set and $55 \%$ versus $45 \%$ for the AFLP data set). The lowest degree of diversity was observed in the comparison between the alternata group and tenuissima group, while the arborescens group resulted the highest genetic distance (Table 4). According to Pearson $\chi^{2}$ and the Pea and Fisher exact test, after an FDR adjustment, no association was revealed between pathogenicity and loci. The principal component analysis (Fig. 7) was used to determine if there were hidden factors, which influenced the clustering of the 44 isolates of Alternaria. PCA of AFLP accounted for $52.1 \%$ of the observed variance with the first three components. In contrast, for the ISSR data set the component values were lower and four components were required to explain $51.81 \%$ of the total vari- 
ance. For both markers, the arborescens morpho-group was the most distinct group. No other groupings, corresponding to geographical areas or pathogenic capability, could be found in this analysis. The relationships among and within the groups obtained with the PCA was concordant with the relationships produced by the cluster analysis, and no further information was added to the data description.

AM-toxin-specific primers PCR. Nine of the forty-four single-spored isolates tested with the AM-toxin-specific primers were positive, producing bands of the same molecular weight (fragments size $500 \mathrm{bp}$ ) as those given by the pathogenic reference strains AKI3, IFO8984, and M71 (Table 3). However, some amplicons were very weak. No amplicons were detected in the remaining isolates or in the reference strain EGS 38-029 (the $A$. mali-type culture). Amplified products were employed as template in a second PCR to increase yield. The sequences obtained from these amplicons were compared with those available in the online database provided by NCBI using the Blast search program. Sequences were affiliated with A. alternata f. sp. mali patho- type (GenBank accession no. AF184074 submitted by Johnson et al. [24]) at $99 \%$ similarity. Differences present consisted of single nucleotides on the third codon position, which were silent transitions. The positive strains did not belong exclusively to any unique morpho-group, did not come from a specific geographical location, and did not exhibit the same grade of pathogenicity.

To investigate the possible causes behind the weak PCR signal from some isolates, new primer sets were designed downstream and upstream of the original primer sites. The sequencing of these new PCR products showed that no differences were present in the original annealing sites of the primers designed by Johnson and collaborators [24] and that low amplification was not due to primer mismatch.

\section{DISCUSSION}

The present study is the first work characterizing pathogenic Alternaria isolates associated with leaf and fruit necrosis of apple in Italy $(32,33)$. This disease is currently causing considerable

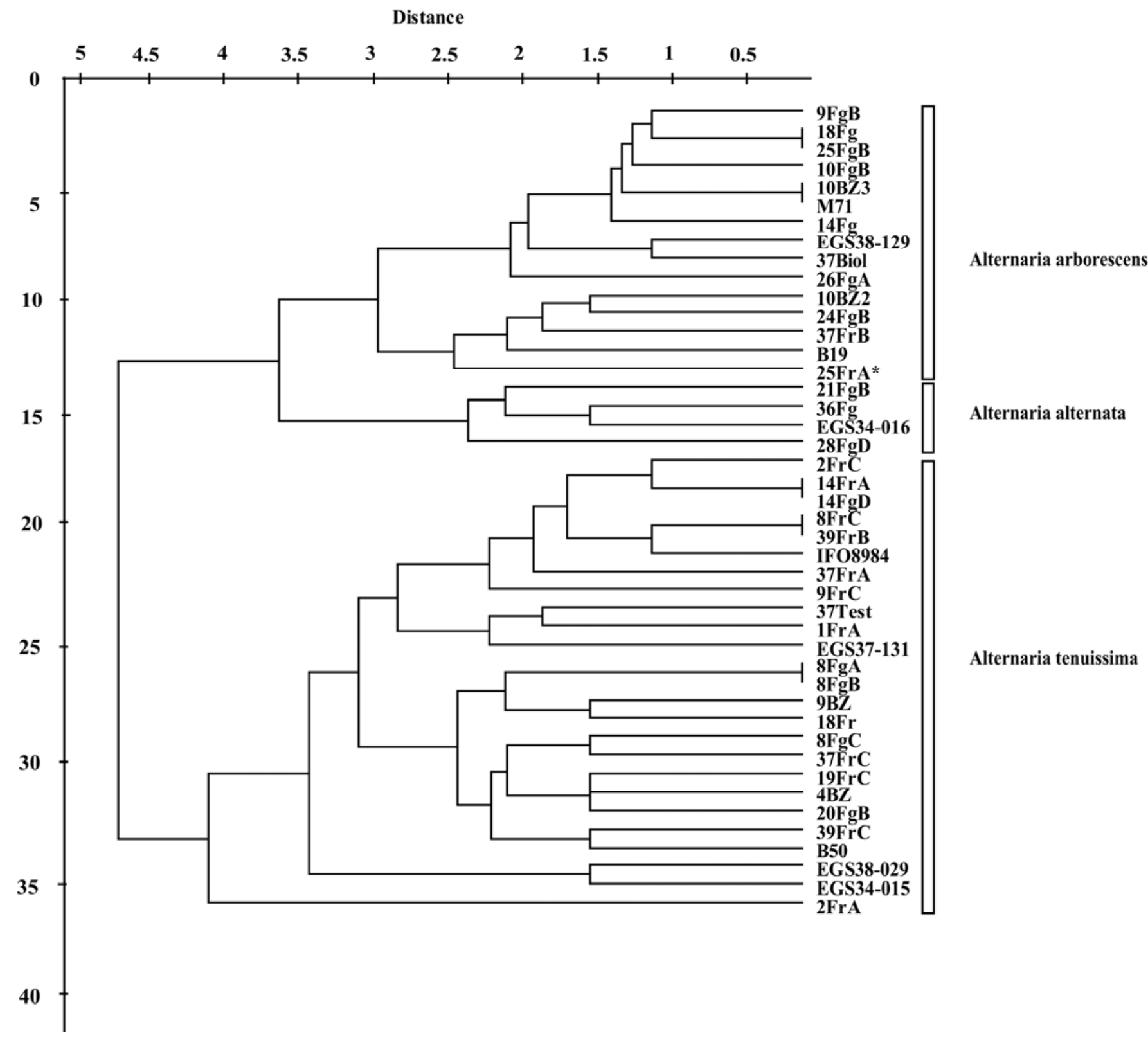

Fig. 4. The cluster analysis based on Euclidian distance, calculated on the scores attributed to the different characteristic of the sporulation habits, shows three distinct clusters that coincide with the three described morpho-groups. The isolate 25FrA* (Alternaria alternata colony morphology) is included in the A. arborescens cluster due to its atypical sporulation. 
damage in orchards in northern Italy and represents a formerly uncharacterized disease. The possibility that these phytopathogens might be conspecific with $A$. mali, causal agent of apple leaf blotch and among the quarantine pests of Europe, provides the impetus for this study.

Morphological study revealed high variability in characters among pathogenic isolates and several main groups could be discriminated. Previous studies have also revealed morphologically distinct groups of small-spored catenulate Alternaria from a number of different host associations, some of which are important HST-mediated diseases $(5,23,46,49)$. The precise definition of the parameters used to investigate the sporulation patterns and the colony morphologies of the apple isolates gave reproducible results in agreement with the features delineated by the previous systematic descriptions in the Pryor and Michaelides study (46) on Alternaria strains recovered from pistachio and in the Hong et al. (23) study on Alternaria spp. recovered from hazelnut and walnut. The identification key utilized identifies distinctive conidia and spore apparatus traits used to ascribe each isolate to a defined morpho-group. The cluster analysis (Euclidian distance similarity) performed on the morphology key scores assigned to each sporulation characteristic clearly showed three groups that correlated very well with the representative isolates previously typified with the exception of one unique strain, 25FrA. Colony morphology descriptions also produced an analogous division, but the categories were not used in clustering analysis due to a more qualitative nature of the data. Nevertheless, there was no discernible pattern among the isolates, both for sporulation habit and the colony morphology, associated with pathogenesis resulting in the pathogenic strains represented among the three groups. Similarly, the apple pathotype reference isolates, including $A$. mali, did not show consistent morphologic traits and were not defined by a specific group.

In vitro bioassays were conducted to discern if there were differences in pathogenic capability among isolates. The use of different plant material (fruit and leaf), wounded and unwounded, immediately highlighted variability in the production of symptoms that correlated with both tissue type and treatment. The

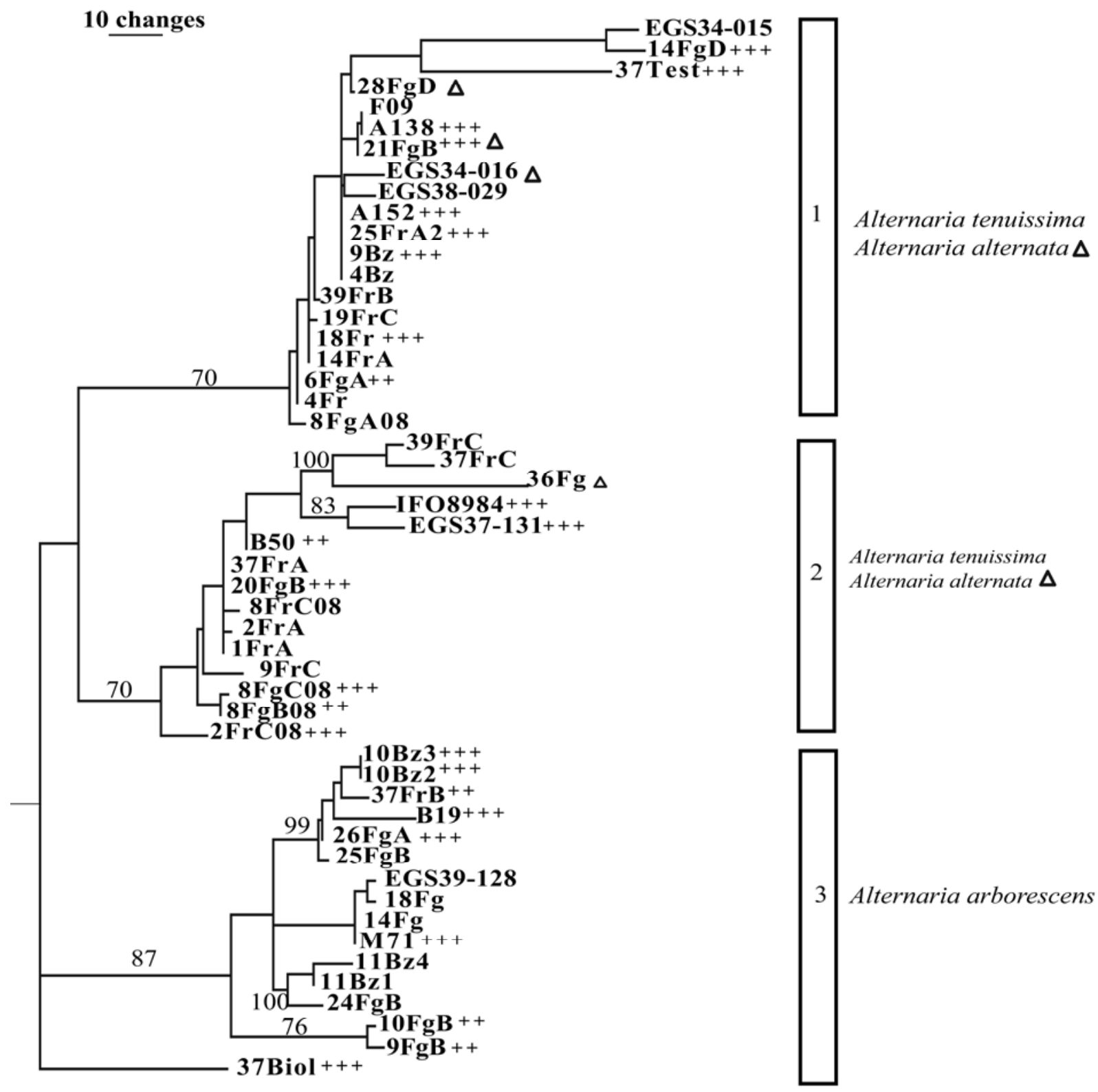

Fig. 5. Majority rules consensus tree (consistency index $=0.63$, retention index $=0.90$ ) obtained from the joint alignment of the combined data sets $($ EndoPg, OPA1-3, OPA2-1, and OPA10-2) using a heuristic search in the maximum parsimony analysis with 1,000 random repetitions. Bootstrap values ( $\geq 70 \%)$ of 1,000 replicates are indicated above the braches. ++ indicates the strains which produced symptoms for at least two of the three pathogenicity test. +++ indicates strains that were positive for all three pathogenicity bioassays. $\Delta$ identifies the $A$. alternata isolates. 
presence of artificial lesions proved to be significant in lesion development, while unwounded material showed reduced lesion development, especially on fruit. Tests on leaf tissues seemed to be the most reproducible and reliable with a good range of symptoms produced. In addition, results revealed a higher percentage of positive lesion development for inoculation on wounded tissues versus unwounded tissues. A commonly reported explanation for this is that tissues that are wounded or weakened due to injury, stress, or senescence are compromised in their defenses and are more susceptible to fungal and other infections $(11,43$, 46,50).
The pathogenicity study of the 44 single-spored strains showed that there was no significant correlation of pathogenicity with either the morphological groupings or the genetic clustering, which was similar to results obtained in previous work $(5,46,55)$. The molecular characterization performed in this study compared different data sets obtained from distinct molecular approaches: (i) sequencing of specific loci and (ii) fingerprinting based on randomly selected polymorphic sites across the genome. However, even with the use of this multimethod approach for characterization of the isolates, the results of this study mirrored previous work in the limited ability to clearly differentiate the groups

\section{A AFLP}

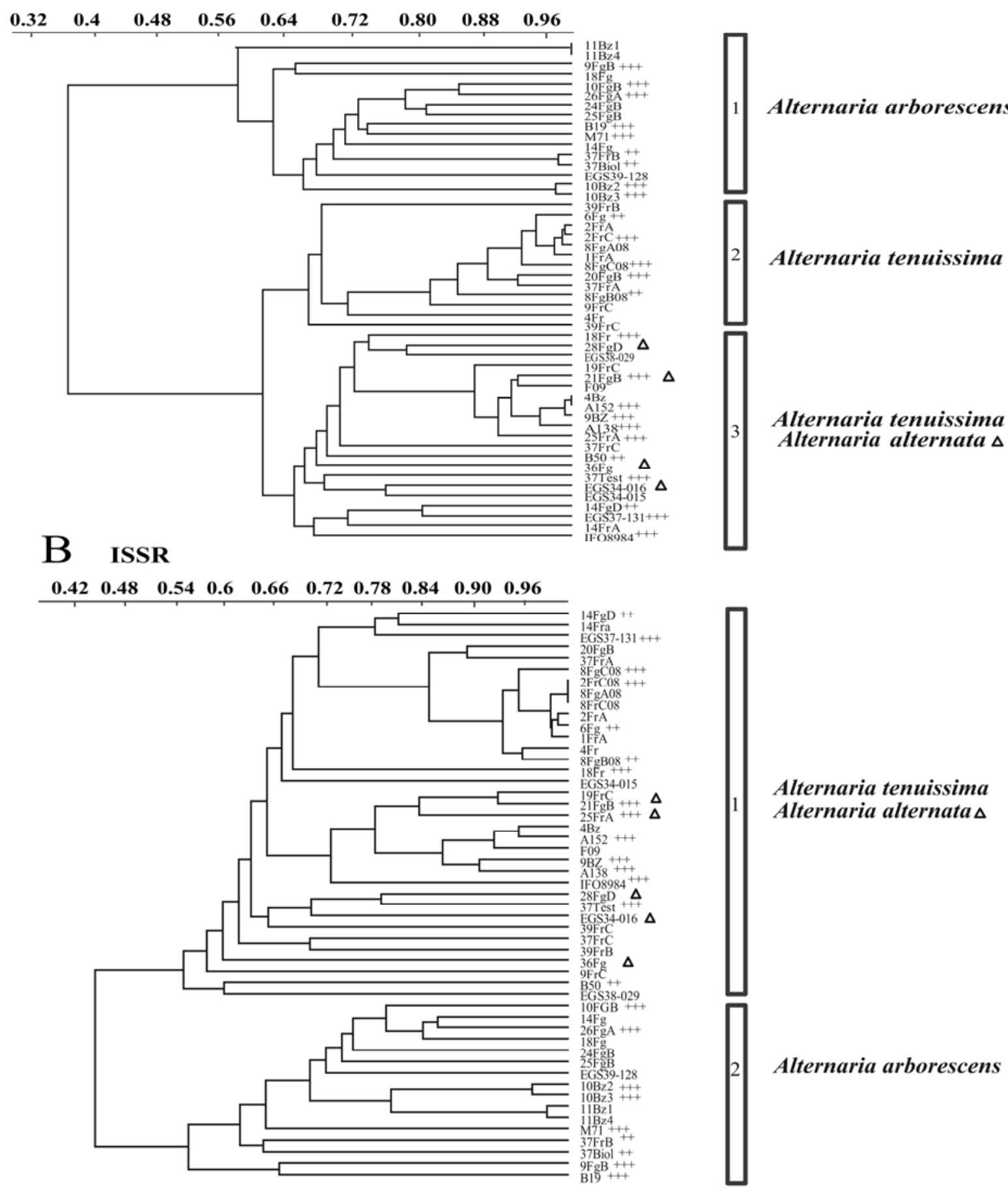

Fig. 6. Cluster analysis, based on Dice's similarity coefficient, of A, the amplified fragment length polymorphism (AFLP) data set and B, the inter simple sequence repeat (ISSR) data set. Vertical bars represent the species group of the isolates. $\Delta$ identifies the Alternaria alternata isolates; ++ indicates that at least two of the three bioassays were positive; and +++ indicates that all bioassays were positive. 
TABLE 4. Differentiation index $\left(\Phi_{\mathrm{T}}\right)$ and Nei's genetic distance (D) calculated among the groups defined by the amplified fragment length polymorphism (AFLP) and inter simple sequence repeat (ISSR) cluster analysis

\begin{tabular}{lllll}
\hline & \multicolumn{1}{c}{ Group 1 } & \multicolumn{1}{c}{ Group 2 } & $\Phi_{\mathrm{T}^{\mathrm{a}}}$ & $\mathrm{D}$ \\
\hline AFLP & Tenuissima group & Alternata-tenuissima group & 0.343 & 0.191 \\
& Tenuissima group & Arborescens group & 0.560 & 0.510 \\
& Alternata-tenuissima group & Arborescens group & 0.426 & 0.379 \\
ISSR & Alternata-tenuissima group & Arborescens group & 0.389 & 0.341 \\
\hline
\end{tabular}

${ }^{a}$ Groups were significantly different $(P<0.05)$ based on $P$ values that were computed from a simulation with 999 permutations.

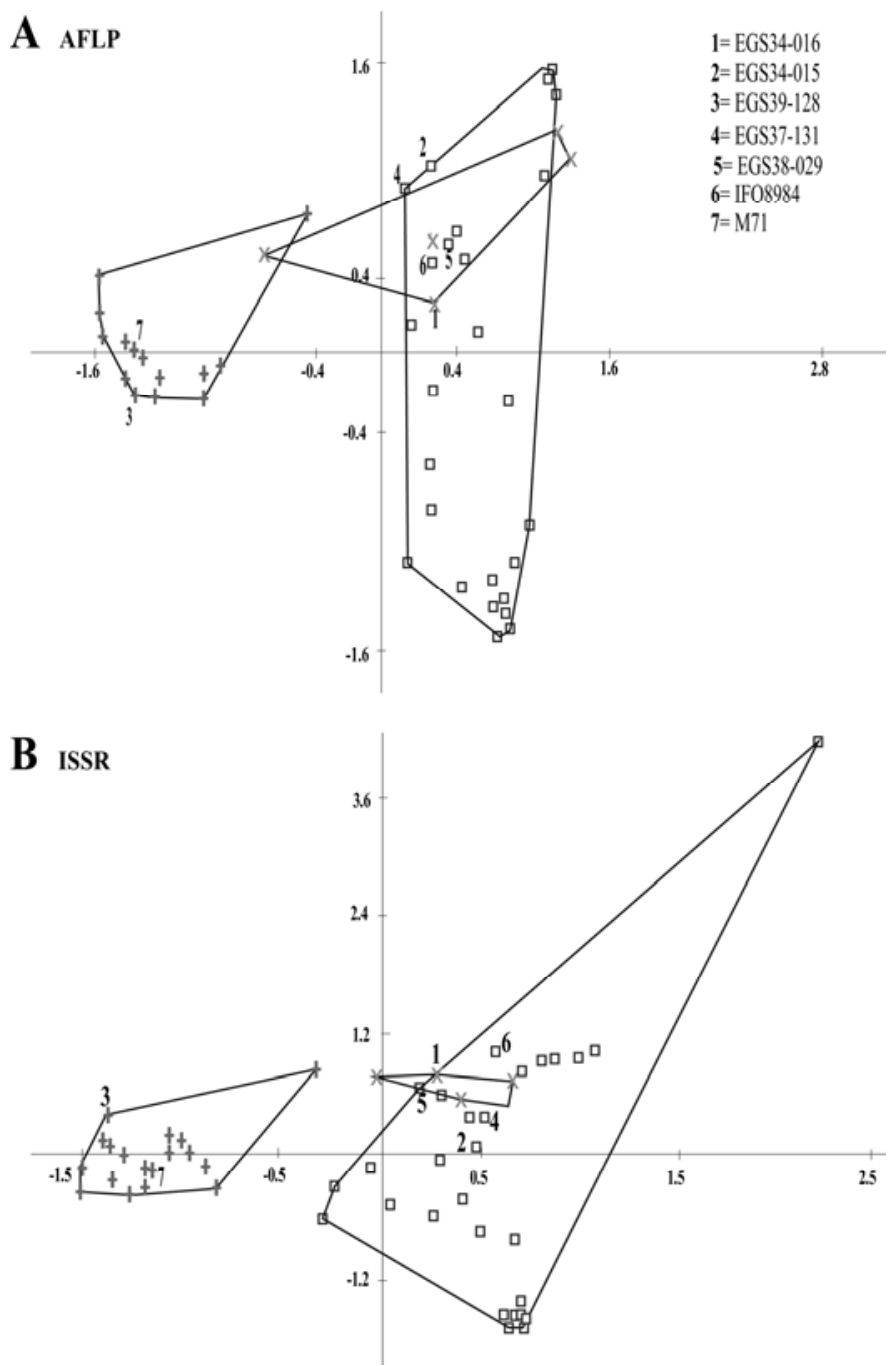

Fig. 7. Distributions of Alternaria alternata $(\times)$, A. tenuissima ( $\square)$, and $A$. arborescens $(+)$ strains computed by principal component analysis, based on the correlation matrices of $\mathbf{A}$, amplified fragment length polymorphism (AFLP) and $\mathbf{B}$, inter simple sequence repeat (ISSR) data sets.

within the study isolates $(5,23,46,54)$. As reported in literature, small-spored Alternaria taxonomy is complicated due to the lack of variability in markers commonly used in fungal systematics, including protein-coding genes $(5,23,42)$. Sequencing of a portion of the endoPG gene and three anonymous regions together provided the necessary variation to establish the phylogenetic relationships among the Italian isolates of Alternaria spp. On Italian strains, these markers showed a variable number of informative sites (ranging from 7 for endoPG to 85 for OPA1-3) and the parsimony analysis produced different tree topologies. Even so, all four markers were able to distinguish the A. arborescens as a phylogenetically distinct clade while not resolving the taxonomic relationship between A. alternata and A. tenuissima $(5,23,54)$. This work provides further support for a hypothesis which poses that the inability to separate these species-groups reliably is likely due to a recent divergence of these taxa, with incomplete lineage sorting, or that these groups, even though recognized as separate species, are still diverging.

Fingerprinting analysis (ISSR and AFLP) also revealed a monophyletic $A$. arborescens clade and a separate clade containing both the alternata and tenuissima morpho-groups. The estimates of the genetic distance computed for each group versus another supported the evidence that $A$. arborescens is a welldefined clade. A Mantel test assessed the strength of the correlation between the AFLP and ISSR data with similar groupings found by the two techniques, and the Mantel test found the correlations were quite strong. AMOVA highlighted that the percentage of molecular variance was higher within the groups than among the groups confirming the existence of diverse haplotypes within the same lineage. The high variability within a group was also observed for the single locus analysis and this explains why clades were not always supported by strong bootstrap values.

This first attempt to characterize Italian Alternaria species recovered from apple produced concordant results with what was already described in a similar phylogenetic study on pistachio (45), walnut and hazelnut (23), apple (54), pear (55), and citrus (42). Together with these studies, this research demonstrates that the three morphological groups are widely distributed and occupy similar ecological niches. Furthermore, this research suggests that these Alternaria species exhibit a similar infection pattern despite the taxonomic and pathogenic differences.

Another aim of this study was to differentiate the pathogenic strain on the basis of molecular profiles. Attainment of this goal would have the most relevant implications concerning the practical management and control of the disease. In fact, the molecular characterization of the pathogen is a fundamental step to understanding the disease that is spreading in the apple orchards of North Italy. Initially, the causal agent was considered to be A. alternata (32). The preliminary studies suggested a pathogenic system related to the synthesis of toxins. Experimental data from our bioassays suggest an analogous hypothesis. In fact, symptoms could often be induced after inoculating plant material solely with the filtrate from pathogenic strains. Interestingly, some strain filtrates were able to produce large lesions, but the strains themselves tested negative for the AM-toxin by PCR amplification. While it was expected that these isolates were producing the host-specific AM-toxin, there is the possibility that some other toxins were responsible for disease development. Additional studies of the chemical composition of the filtrate may be necessary, using techniques such as high-performance liquid chromatography or mass spectroscopy for the AM-toxin I and other toxic secondary metabolites. The studying of secondary metabolite profiles has proved to be an informative method for highlighting differences among small-spored Alternaria where the molecular and morphological characterizations have failed $(3,4)$.

Moreover, positive PCR detection of the AM-toxin gene in some isolates using AM-toxin gene-specific primers support the hypothesis that an HST is involved in pathogenicity by some isolates. However, detection of the AM genes was not positive for all isolates suggesting that other mechanisms of pathogenesis may additionally be involved. Thus, it remains an intriguing challenge to discover if any of the agents of the Italian disease are the same 
as the one previously typified as A. mali, causal agent of the apple blotch disease.

A number of important conclusions were derived from this research. First, pathogenicity on apple is not an exclusive character of a specific morpho-group or phylogenetic clade but is acquired by isolates independently. Studies on the molecular basis of HST synthesis in Alternaria (2) have demonstrated that the genes involved in AM-toxin host-specific interaction are clustered on a conditionally dispensable chromosome (CDC). That horizontal transmission of these chromosomes among closely related fungi can occur has also been demonstrated (1). It is possible that these closely related species are sharing these CDCs. This is particularly evident from the case of strain M71, which showed a typical arborescens sporulation pattern and genotype while the other three strains showed typical tenuissima sporulation patterns and genotypes. While it was not the specific goal to examine the distribution of the AM-toxin gene throughout small-spored Alternaria spp., its presence among several distinct Alternaria species presents an interesting area of future research. These findings also highlight the need to further investigate the possibility of horizontal CDC transfer among closely related taxa. Different species names such as A. mali and A. alternata have been associated with Alternaria blotch of apple, but the presence of the HST is the common factor for symptom development in susceptible apple cultivars (27). However, this research reveals that it is not possible to strictly define a single taxon or species as the causal agent of Alternaria blotch of apple. Combining these results with the results of other studies examining different aspects of the disease (toxin characterization, host susceptibility, etc.) will more clearly define the relationships between A. alternata apple pathotype, the Italian Alternaria populations, and the capability to produce toxic secondary metabolite and lay the foundation for improved disease management in Italy and other countries.

\section{ACKNOWLEDGMENTS}

This work was supported in part by the University of Arizona, College of Agriculture and Life Sciences, the University of Bologna, College of Agricultural Science, PRIN 2008 National research funds (Prot. no. 2008ZNA4Z3), and the National Science Foundation (NSF DEB grant no. 0416283). We thank Servizio Fitosanitario Regione Veneto, Servizio Fitosanitario Regione Emilia-Romagna, Servizio Fitosanitario Regione Friuli Venezia Giuglia, Laimburg Research Center for Agriculture and Forestry (in particular Dr. Klaus Marschall), Istituto Agrario di San Michele all' Adige (in particular (Gastone Dallago).

\section{LITERATURE CITED}

1. Akagi, Y., Akamatsu, H., Otani, H., and Kodama, M. 2009. Horizontal chromosome transfer, a mechanism for the evolution and differentiation of a plant-pathogenic fungus. Eukaryotic Cell 8:1732-1738.

2. Akamatsu, H., Taga, M., Kodama, M., Johnson, R., Otani, H., and Kohmoto, K. 1999. Molecular karyotypes for Alternaria plant pathogens known to produce host-specific toxins. Curr. Gen. 35:647-656.

3. Andersen, B., Krøger, E., and Roberts, R. G. 2002. Chemical and morphological segregation of Alternaria arborescens, A. infectoria and A. tenuissima species-groups. Mycol. Res. 106:170-182.

4. Andersen, B., Smedsgaard, J., Jørring, I., Skouboe, P., and Pedersen, L. H. 2006. Real-time PCR quantification of the AM-toxin gene and HPLC qualification of toxigenic metabolites from Alternaria species from apples. Int. J. Food Microbiol. 111:105-111.

5. Andrew, M., Peever, T. L., and Pryor, B. M. 2009 An expanded multilocus phylogeny does not resolve morphological species within the smallspored Alternaria species complex. Mycologia 10:95-109.

6. Antoniacci L., and Montuschi, C. 2006. Ecco come si riconosce la filloptosi del melo. Agricoltura 7-8:78-79.

7. Bassam, B. J., and Caetano-Allones, G. 1993. Silver staining of DNA in polyacrylamide gels. Appl. Biochem. Biotechnol. 42:181-188.

8. Benjamini, Y., and Hochberg, Y. 1995. Controlling the false discovery rate: A practical and powerful approach to multiple testing. J. Roy. Stat. Soc. B Sta. 57:289-300.
9. Berbee, M. L. 2001. The phylogeny of plant and animal pathogens in the ascomycota. Physiol. Mol. Plant Pathol. 59:165-187.

10. Berbee, M. L., Pirseyedi, M., and Hubbard, S. 1999. Cochliobolus phylogenetics and the origin of known, highly virulent pathogens, inferred from ITS and glyceraldehyde-3-phosphate dehydrogenase gene sequences. Mycologia 91:964-977.

11. Blodgett, J. T., and Swart, W. J. 2002. Infection, colonization, and disease of Amaranthus hybridus leaves by the Alternaria tenuissima group. Plant Dis. 86:1199-1205.

12. Bulajic, A., Filajdic, N., Babovic, M., and Sutton, T. B. 1996. First report of Alternaria mali on apples in Yugoslavia. Plant Dis. 80:709.

13. Dice, L. R. 1945. Measures of the amount of ecologic association between species. Ecology 26:97-302.

14. Eikemo, H., Klemsdal, S. S., Riisberg, I., Bonants, P., Stensvand, A., and Tronsmo, A. M. 2004. Genetic variation between Phytophthora cactorum isolates differing in their ability to cause crown rot in strawberry. Mycol. Res. 108:317-324.

15. Excoffier, L., Smouse, P. E., and Quattro, J. M. 1992. Analysis of molecular variance inferred from metric distances among DNA haplotypes: Application to human mitochondrial DNA restriction data. Genetics 131:479-491.

16. Farr, D. F., Bills, G. F., Chamuris, G. P., and Rossman, A. Y. 1989. Fungi on Plants and Plant Products in the United States. American Phytopathological Society, St. Paul, MN.

17. Filajdic, N., and Sutton, T. B. 1991. Identification and distribution of Alternaria mali in North Carolina and susceptibility of different varieties of apples to Alternaria blotch. Plant Dis. 78:719-724.

18. Gannibal, P. B., Klemsdal, S. S., and Levitin, M. L. 2007. AFLP analysis of Russian Alternaria tenuissima populations from wheat kernels and other hosts Eur. J. Plant Pathol. 119:175-182.

19. Gobber, M., Mattedi, L., Forno, F., Cappello, S., Piva, U., Marschall, K., and Rizzolli, W. 2004. Nuova malattia del melo causata dal fungo Alternaria alternata. Terra Trentina 6:31-36.

20. Hall, T. 2004. BioEdit version 7.0.0. Distributed by the author. Published online. http://www.mbio.ncsu.edu/BioEdit/bioedit.html

21. Hammer, Ø., Harper, D. A. T., and Ryan, P. D. 2001. PAST: Paleontological Statistics Software Package for Education and Data Analysis. Palaeontologia Electronica 4:9. http://palaeo-electronica.org/2001_1/ past/issue1_01.htm

22. Hatta, R., Ito, K., Hosaki, Y., Tanaka, T., Tanaka, A., Yamamoto, M., Akimitsu, K., and Tsuge, T. 2002. A conditionally dispensable chromosome controls host-specific pathogenicity in the fungal plant pathogen Alternaria alternata. Genetics 161:59-70.

23. Hong, H., Maccaroni, M., Figuli, P. J., Pryor, B. M., and Bellisario, A. 2006. Polyphasic classification of Alternaria isolated from hazelnut and walnut fruit in Europe. Mycol. Res. 110:1290-1300.

24. Johnson, R. D., Johnson, L., Itoh, Y., Kodama, M., Otani, H., and Kohmoto, K. 2000. Cloning and characterization of a cyclic peptide synthetase gene from Alternaria alternata apple pathotype whose product is involved in AM-toxin synthesis and pathogenicity. Mol. Plant-Microbe Interact. 12:742-753.

25. Johnson, R. D., Johnson, L., Kohmoto, K., Otani, H., Lane, C. R., and Kodama, M. 2000. A polymerase chain reaction-based method to specifically detect Alternaria alternata apple pathotype (A. mali), the causal agent of Alternaria blotch of apple. Phytopathology 9:973-976.

26. Jolliffe, I. T. 1986. Principal Component Analysis. Springer-Verlag, New York.

27. Kohmoto, K., Taniguchi, T., and Nishimura, S. 1974. Correlation between the susceptibility of apple cultivars to Alternaria mali and their sensitivity to AM-toxin I. Ann. Phytopathol. Soc. Jpn. 43:65-66.

28. Maddison, W. P., and Maddison, D. R. 1989. Interactive analysis of phylogeny and character evolution using the computer program MacClade. Folia Primatol. 53:190-202.

29. Maddison, W. P., and Maddison, D. R. 2009. Mesquite: A modular system for evolutionary analysis. Version $2.72 \mathrm{http}: / /$ mesquiteproject.org

30. Mantel, N. 1967. The detection of disease clustering and a generalized regression approach. Cancer Res. 27:209-220.

31. Markham, J. E., and Hille, J. 2001. Host-selective toxins as agents of cell death in plant-fungus interactions. Mol. Plant Pathol. 2:229-239.

32. Marschall, K., and Bertagnoll, M. 2006. Patotipo di Alternaria alternata agente di maculatura lenticellare su frutti e di necrosi fogliari su melo in Alto Adige. Atti Giornate Fitopatologiche 2:93-96.

33. Marschall, K., Rizzolli, W., and Bradlwarter, M. 2004. La lenticellosi da Alternaria-la difesa. Frutta e Vite 3:85-87.

34. Masunaka, A., Tanaka, A., Tsuge, T., Peever, T. L., Timmer, L. W., Yamamoto, M., Yamamoto, H., and Akimitsu, K. 2000. Distribution and characterization of AKT homologs in the tangerine pathotype of Alternaria alternata. Phytopathology 90:762-768.

35. Nei, M. 1972. Genetic distance between populations. Am. Nat. 106:283292. 
36. Nishimura, S., and Kohmoto, K. 1983. Host-specific toxins and chemical structures from Alternaria species. Annu. Rev. Phytopathol. 21: 87-116.

37. Nobles, M. K. 1948. Studies in forest pathology. VI. Identification of cultures of wood-rotting fungi. Can. J. Forest Res. 26:281-431.

38. Oliver, R. P., and Solomon, P. S. 2008. Recent fungal diseases of crop plants: Is lateral gene transfer a common theme? Mol. Plant-Microbe Interact. 21:287-293.

39. Ortalda, E. 2006. Indagine sulla presenza di Alternaria alternata su melo in Piemonte. Pages 55-57 in: Annali del Settore Fitosanitario Regionale Piemonte.

40. Park, P., Tsuda, M., Hayashi, Y., and Ueno, T. 1977. Effect of host specific toxin (AM-toxin1) produced by Alternaria mali, an apple pathogen, on the ultrastructure of plasma membrane of cells of apple and Japanese pear leaves. Can. J. Bot. 55:2383-2387.

41. Peakall, R., and Smouse, P. E. 2006. GENALEX 6: Genetic analysis in Excel. Population genetic software for teaching and research. Mol. Ecol. Notes 6:288-295.

42. Peever, T. L., Su, G., Carpenter-Boggs, L., and Timmer, L. W. 2004. Molecular systematics of citrus-associated Alternaria species. Mycologia 96:119-134.

43. Pleysier, C. E., Bayliss, K. L., Dell, B., and Hardy, G. E. St. J. 2006. Temperature, humidity, wounding and leaf age influence the development of Alternaria alternata lesions on leaves of Paulownia fortunei. Austral. Plant Pathol. 35:329-333.

44. Pryor, B. M., and Bigelow, D. M. 2003. Molecular characterization of Embellisia and Nimbya species and their relationship to Alternaria, Ulocladium, and Stemphylium. Mycologia 95:1139-1152.

45. Pryor, B. M., and Gilbertson, R. L. 2000. Molecular phylogenetic relationships amongst Alternaria species and related fungi based on analysis of nuclear ITS and mt SSU rDNA sequences. Mycol. Res. 104:13121321.

46. Pryor, B. M., and Michaelides, T. J. 2002. Morphological, pathogenic and molecular characterization of Alternaria isolate associated with Alternaria late blight of pistachio. Phytopathology 92:406-415.

47. Ridgway, R. 1912. Color Standards and Color Nomenclature. Published by the Author. Washington, DC.

48. Roberts, J. W. 1924. Morphological character of Alternaria mali Roberts. J. Agric. Res. 27:699-708.

49. Roberts, R. G., Reymond, S. T., and Andersen, B. 2000. RAPD fragment pattern analysis and morphological segregation of small-spored Alternaria species and species groups. Mycol. Res. 104:151-160.

50. Rotem, J. 1994. The Genus Alternaria. Biology, Epidemiology and Pathogenicity. American Phytopathological Society, St. Paul, MN.
51. Sawamura, K. 1962. Studies on spotted diseases of apple. 1. Causal agent of Alternaria blotch. Bull. Tohoku National Agric. Exp. Stn. 23:163-175.

52. Sawamura, K. 1972. Studies on apple Alternaria blotch caused by Alternaria mali Roberts. Fac. Agric. Hirosaki Univ. Bull. 18:152-235.

53. Sawamura, K. 1990. Alternaria blotch. Pages 24-25 in: Compendium of Apple and Pear Diseases. A. L. Jones and H. Aldwinckle, eds. American Phytopathological Society, St. Paul, MN.

54. Serdani, M., Kang, J. C., Peever, T. L., Andersen, B., and Crous, P. W. 2002. Characterisation of Alternaria species groups associated with core rot of apples in South Africa. Mycol. Res. 106:562-570.

55. Simmons, E. G. 1992. Alternaria themes and variations (73). Mycotaxon 48:109-140.

56. Simmons, E. G. 1999. Alternaria themes and variations (236-243). Mycotaxon 70:325-369.

57. Simpson, E. H. 1949. Measurement of diversity. Nature 163:688.

58. Swofford, D. L. 2000. PAUP*. Phylogenetic analysis using parsimony (and other methods). Version 4. Sinauer Associates, Sunderland, MA.

59. Tanaka, A., Shiotani, H., Yamamoto, M., and Tsuge, T. 1999. Insertional mutagenesis and cloning of the genes required for biosynthesis of the host-specific AK-toxin in the Japanese pear pathotype of Alternaria alternata. Mol. Plant-Microbe Interact. 12:691-702.

60. Thomma, B. P. H. J. 2003. Alternaria spp.: From general saprophyte to specific parasite. Mol. Plant Pathol. 4:225-236.

61. Thompson, J. D., Higgins, D. G., and Gibson, T. J. 1994. CLUSTAL W: Improving the sensitivity of progressive multiple sequence alignment through sequence weighting, position-specific gap penalties and weight matrix choice. Nucleic Acids Res. 11:4673-4680.

62. Tymon, A. M., and Pell, J. K. 2005. ISSR, ERIC and RAPD techniques to detect genetic diversity in the aphid pathogen Pandora neoaphidis. Mycol. Res. 109:285-293.

63. van der Does, H. C., and Rep, M. 2007. Virulence genes and the evolution in plant-pathogenic fungi. Mol. Plant-Microbe Interact. 20:1175-1182.

64. Vos, P., Hogers, R., Bleeker, M., Reijans, M., van de Lee, T., Hornes, M., Frijters, A., Pot, J., Kuiper, M., and Zabeau, M. 1995. AFLP: A new technique for DNA fingerprinting. Nucleic Acids Res. 23:4407-4414.

65. Walton, J. D. 2000. Horizontal gene transfer and the evolution of secondary metabolite gene clusters in fungi: A hypothesis. Fungal Genet. Biol. 30:167-171.

66. Wolpert, T. J., Dunkle, L. D., and Ciuffetti, L. M. 2002. Host-selective toxins and avirulence determinants: What's in a name? Annu. Rev. Phytopathol. 40:251-285.

67. Zhou, S., Smith, D. R., and Stanosz, G. R. 2001. Differentiation of Botryosphaeria species and related anamorphic fungi using inter simple or short sequence repeat (ISSR) fingerprinting. Mycol. Res. 105:919-926. 